\title{
The role of translation elongation factor eEF1A in intracellular alkalinization-induced tumor cell growth
}

\author{
Juno Kim', Wan Namkung ${ }^{1}$, Jae Seok Yoon, Min Jae Jo, Sung Hee Lee, Kyung Hwan Kim, Joo Young Kim \\ and Min Goo Lee
}

The formation of a pH gradient, which is characterized by intracellular alkalinization and extracellular acidification, plays a key role in the growth and metastasis of tumor cells. However, the underlying mechanisms of alkalinization-induced cell growth are not known. In this study, we investigated the roles of eukaryotic translation elongation factor $1 \alpha(\mathrm{eEF} 1 \mathrm{~A})$ in alkalinization-induced cell growth. In all cell lines tested (NIH3T3, HEK293, and HeLa), cell growth was affected by the modulation of intracellular $\mathrm{pH}$. In general, weak intracellular alkalinization produced increased cell growth, whereas intracellular acidification resulted in decreased cell growth. It is interesting to note that portions of actin-bound eEF1A proteins were gradually reduced from acidic to alkaline conditions, suggesting an increase in levels of functionally active, free-form eEF1A. Over-expression of eEF1A caused increased cell growth in HeLa cells. It should be noted that dissociation of eEF1A from actin by transfection with the actin-binding domain deleted eEF1A construct further increased cell growth under acidic conditions, whereas most of the intact eEF1A was bound to actin. Conversely, knockdown of eEF1A by treatment with eEF1A1 and eEF1A2 siRNAs nullified the effects of alkalinization-induced cell growth. The above findings suggest that an increase in free-form eEF1A under alkaline conditions plays a critical role in alkalinization-induced cell growth.

Laboratory Investigation (2009) 89, 867-874; doi:10.1038/labinvest.2009.53; published online 8 June 2009

KEYWORDS: actin; alkalinization; cancer; cell growth; eEF1A; $\mathrm{Na}^{+} / \mathrm{H}^{+}$exchanger

Tumor cells that harbor a significant growth advantage have several different hallmarks including a high degree of intracellular alkalinization and an abnormal glycolytic metabolism. ${ }^{1}$ Cellular alkalinization is one of the most common phenotypes of tumor cells and it is because of their ability to secrete protons, and acidify their extracellular environment. Alkaline intracellular $\mathrm{pH}\left(\mathrm{pH}_{\mathrm{i}}\right)$ and acidic extracellular $\mathrm{pH}$ $\left(\mathrm{pH}_{\mathrm{e}}\right)$ create a reversed $\mathrm{pH}$ gradient across the cell membrane, which is the earliest step of neoplastic progression. ${ }^{1,2}$ Tumor cells activate membrane-based ion exchangers, such as the $\mathrm{Na}^{+} / \mathrm{H}^{+}$exchanger 1 (NHE1), the $\mathrm{Cl}^{-} / \mathrm{HCO}_{3}^{-}$exchanger, $\mathrm{H}^{+}$-ATPase proton pump, and the $\mathrm{H}^{+}$/lactate co-transporter to maintain the reverse $\mathrm{pH}$ gradient. ${ }^{3-5}$

NHE1, the housekeeping isoform of the $\mathrm{Na}^{+} / \mathrm{H}^{+}$ exchanger, is ubiquitously distributed in most tissues and has an important role in the regulation of $\mathrm{pH}_{\mathrm{i}}$ by exchanging intracellular protons $\left[\mathrm{H}^{+}\right]_{\mathrm{i}}$ for extracellular sodium $\left[\mathrm{Na}^{+}\right]_{\mathrm{e}} \cdot{ }^{6-8}$ The transformed cells and tumor cells differ from normal tissues in that they have constitutive NHE1 activity at resting $\mathrm{pH}_{\mathrm{i}}$, resulting in an increased $\mathrm{pH}_{\mathrm{i}}{ }^{1,9}$ Intracellular alkalinization induced by the activation of NHE1 in tumor cells has been shown to play key role in the maintenance and progression of the neoplastic state. For example, transformation of human keratinocytes by the E7 oncogene of human papillomavirus type 16 showed NHE1 activation as a key mechanism in malignant transformation. ${ }^{10}$ This activation of NHE1, with consequent cytoplasmic alkalinization, appears to be involved in the universal regulation of tumor progression when quiescent cells commit to proliferate. ${ }^{10,11}$ However, the underlying molecular mechanisms of alkalinization-induced cell growth are still poorly understood.

One of the key proteins in cell proliferation and growth is eukaryotic elongation factor $1 \propto(\mathrm{eEF} 1 \mathrm{~A})$. During protein translation, eEF1A recruits aminoacyl t-RNA to the ribosome and translocates the growing polypeptide from the ribosomal A site to the P site. ${ }^{12}$ eEF1A is one of the most abundant

Department of Pharmacology and Brain Korea 21 Project for Medical Science, Yonsei University College of Medicine, Seoul, Korea

Correspondence: Dr JY Kim, PhD, Department of Pharmacology, Yonsei University College of Medicine, 250 Sungsan-ro, Seoul 120-752, Korea.

E-mail: jooyoungkim@yuhs.ac

${ }^{1}$ These authors contributed equally to this work.

Received 28 October 2008; revised 21 April 2009; accepted 21 April 2009 
proteins in the cell, comprising $1-2 \%$ of total proteins, and is highly conserved. ${ }^{13-15}$ There are two human isoforms of eEF1A, eEF1A1 and eEF1A2, which share more than $90 \%$ homology by amino-acid sequencing. eEF1A1 is expressed ubiquitously, whereas eEF1A2 expression is restricted to the heart, the brain, and the skeletal muscles in humans and rodents. ${ }^{16,17}$ It has been shown that increased expression of eEF1A1 and eEF1A2 proteins is associated with increased cell proliferation, oncogenic transformation, and delayed cell senescence. ${ }^{14,18,19}$

It is interesting to note that cellular redistribution of eEF1A is related to $\mathrm{pH}_{\mathrm{i}} \cdot{ }^{14,19}$ The eEF1A proteins in many species bind to actin filaments and microtubules both in vivo and in vitro. ${ }^{20}$ The binding affinity of eEF1A for F-actin diminishes with increasing $\mathrm{pH}_{\mathrm{i}}$, and eEF1A dissociates from F-actin in alkaline conditions. In Dictyostelium, the total amount of free-form eEF1A increases by $60 \%$ upon intracellular alkalinization from $\mathrm{pH} 6.0$ to $8.0 .{ }^{19}$ In general, it is believed that eEF1A and other translational cofactors are complexed with F-actin in specific regions of the cell, and a $\mathrm{pH}$-sensitive transition in cytoskeletal association increases translational efficiency. ${ }^{19}$ Therefore, it is possible that the actin-binding properties of eEF1A and its cellular distribution are the primary targets in alkalinization-dependent tumor cell growth.

The present study was undertaken to investigate the role of eEF1A proteins in intracellular alkalinization-induced cell growth using an integrated molecular functional approach. The results in this study indicate that an increase in the amount of unbound free-form eEF1A under alkaline conditions has an important role in alkalinization-induced cell growth.

\section{MATERIALS AND METHODS Materials}

We purchased 2',7'-bis(2-carboxyethyl)-5(6)-carboxyfluorescein acetoxymethylester (BCECF-AM) was purchased from Molecular Probes (Eugene, OR, USA). Anti-eEF1A and anti-Myc monoclonal antibodies were obtained from Upstate (Lake Placid, NY, USA) and Santa Cruz Biotechnology (Santa Cruz, CA, USA), respectively. Actin-biotin and immobilized streptavidin were purchased from Cytoskeleton (Denver, CO, USA) and PIERCE (Rockford, IL, USA), respectively. Cariporide, the NHE1 inhibitor, was synthesized at the Korea Research Institute of Chemical Technology (Daejon, Korea). ${ }^{21}$ All other chemicals including 3-(4, 5-dimethylthiazol2-yl)-2, 5-diphenyltetrazolium bromide (MTT), and sodium dodecyl sulfate (SDS) were purchased from Sigma (St. Louis, MO, USA). Original constructs of human eEF1A1 (pCMVSPORT6) and eEF1A2 (pCNS) were purchased from the Korea Research Institutive of Bioscience and Biotechnology (Daejon, Korea). pCMV-eEF1A1, pCMV-eEF1A2, pCMVeEF1A1 $\Delta 408-462$, and pCMV-eEF1A2 $\Delta 408-463$ with carboxy-terminal Myc tag were PCR-amplified and sub- cloned into the pcDNA $3.1 / \mathrm{Zeo}(+)$ vector using the EcoRI and XbaI sites.

\section{Cell Cultures and Cell Viability Assay}

NIH3T3, HEK293, and HeLa cells were maintained in Dulbecco's modified Eagle's medium-high glucose medium (DMEM-HG; Invitrogen, Carlsbad, CA, USA), supplemented with $10 \%$ heat-inactivated fetal bovine serum (FBS; Life Technologies, Gaithersburg, MD, USA), penicillin $(50 \mathrm{IU} / \mathrm{ml})$, and streptomycin $(50 \mu \mathrm{g} / \mathrm{ml})$ at $37^{\circ} \mathrm{C}$ in $10 \% \mathrm{CO}_{2}$ incubator. Cells grown in alkaline or acidic conditions were incubated in 2 and $20 \% \mathrm{CO}_{2}$ incubators, respectively. In addition, a batch of cells were cultured in another acidic medium, where the standard $44 \mathrm{mM} \mathrm{NaHCO}_{3}$ of DMEM was replaced with $10 \mathrm{mM} \mathrm{NaHCO}_{3}$ and $34 \mathrm{mM} \mathrm{NaCl}$, and incubated at $10 \% \mathrm{CO}_{2}$ to minimize the possible adverse effects from high $\mathrm{CO}_{2}$ concentrations. Cells were seeded onto 12 -well plates at a density of $1.2 \times 10^{5}$ cells $/ \mathrm{mm}^{2}$. Following initial 12 -h incubation in the standard DMEM at $10 \% \mathrm{CO}_{2}$, the medium was replaced with DMEM-HG pre-incubated at 2, 10, or $20 \% \mathrm{CO}_{2}$, or with $\mathrm{HCO}_{3}^{-}$-modified DMEM-HG pre-incubated at $10 \% \mathrm{CO}_{2}$, and the cells were continuously kept on incubation chambers bearing corresponding $\mathrm{CO}_{2}$ concentrations. In one set of experiments, the NHE1 inhibitor cariporide $(100 \mu \mathrm{M})$ was added to the medium. All medias were changed every $12 \mathrm{~h}$ until the end of the experiment.

The cell proliferation of each sample was determined by MTT assay. MTT stock solution $(5 \mathrm{mg} / \mathrm{ml}$ in phosphatebuffered saline) was added to samples, giving a final MTT concentration of $1 \mathrm{mg} / \mathrm{ml}$. After the incubation, cells were treated overnight with 1 volume of lysis buffer (20\% SDS in $50 \% \mathrm{~N}, \mathrm{~N}$-dimethyl formamide with water, $\mathrm{pH} 4.7)$. The spectrophotometric absorbance of each sample was measured at $570 \mathrm{~nm}$ using a Spectra Microplate Reader (Molecular Devices, Sunnyvale, CA, USA).

\section{Intracellular pH Measurements}

Intracellular $\mathrm{pH}\left(\mathrm{pH}_{\mathrm{i}}\right)$ was measured as previously described. ${ }^{22}$ Briefly, cells were cultured on coverslips with the standard DMEM-HG at 2, 10 , or $20 \% \mathrm{CO}_{2}$, or with the $\mathrm{HCO}_{3}^{-}$-modified DMEM-HG at $10 \% \mathrm{CO}_{2}$ for 1 day. The cells were then washed with pre-incubated $\mathrm{HCO}_{3}^{-}$-buffered solution at each $\mathrm{CO}_{2}$ concentration and assembled to form the bottom of a perfusion chamber. The $\mathrm{HCO}_{3}^{-}$-buffered solution contained 110 (or 144) $\mathrm{NaCl}, 5 \mathrm{KCl}, 1 \mathrm{MgCl}_{2}, 1 \mathrm{CaCl}_{2}$, 10 D-glucose, and 44 (or 10) $\mathrm{NaHCO}_{3}$. (in $\mathrm{mM} / \mathrm{L}$ ). The cells were loaded with the fluorescent $\mathrm{pH}$ probe BCECF by incubating for $10 \mathrm{~min}$ in each solution containing $2.5 \mu \mathrm{M}$ BCECF-AM. After dye loading, cells were perfused with the appropriate solutions, and the $\mathrm{pH}_{\mathrm{i}}$ was measured by photon counting using a fluorescence measuring system (Delta Ram; PTI Inc., South; Brunswick, NJ, USA). The fluorescence ratios of $490 / 440 \mathrm{~nm}$ were calibrated intracellularly by perfusing the cells with solutions containing $145 \mathrm{mM} \mathrm{KCl}$, 
$10 \mathrm{mM}$ HEPES, and $5 \mathrm{im}$ nigericin, with the $\mathrm{pH}$ adjusted to $6.2-7.8$.

\section{RNA Preparation and RT-PCR}

The expression of eEF1As in NIH3T3, HEK293, and HeLa cells was examined by reverse transcription (RT)-PCR. Total RNA was prepared from NIH3T3, HEK293, and HeLa cells using Trizol solution (Invitrogen, Carlsbad, CA, USA) and reverse-transcribed using random hexa-primers and an RNase $\mathrm{H}^{-}$reverse transcriptase (Invitrogen). The cDNA was amplified using specific primers and a Taq polymerase (Promega, Madison, WI, USA), and the products were separated on $1 \%$ agarose gel containing $0.1 \mu \mathrm{g} / \mathrm{ml}$ ethidium bromide. The primer sequences used are shown in Supplementary 1.

\section{Actin Binding Assay and Immunoblotting}

The pCMV-eEF1A1, pCMV-eEF1A2, pCMV-eEF1A1 $\Delta 408-462$, and pCMV-eEF1A2 $\Delta 408-463$ with Myc epitope constructs were transiently transfected into HeLa cells in a $100-\mathrm{mm}$ dish using the Lipofectamin Plus Reagent (Invitrogen, Carlsbad, CA, USA). After $48 \mathrm{~h}$ of incubation, cells were lysed with one of three kinds of $\mathrm{pH}$-modulated actin binding buffers (20 mM PIPES pH 6.0, $20 \mathrm{mM}$ Tris- $\mathrm{HCl} \mathrm{pH} 7.0$, or $20 \mathrm{mM}$ Tris- $\mathrm{HCl} \mathrm{pH} 8.0$ solution containing $50 \mathrm{mM} \mathrm{KCl}$, $2 \mathrm{mM} \mathrm{MgCl}_{2}, 1 \mathrm{mM}$ ATP, $1 \%$ Triton X-100, $0.2 \mathrm{mM} \mathrm{DTT}$, $2 \mathrm{mM}$ EGTA, and complete proteinase inhibitor cocktails). Protein samples $(1.5 \mathrm{mg})$ from cells expressing each construct were resuspended in the appropriate actin binding buffers and incubated with $10 \mu \mathrm{g}$ of actin-biotin at $4^{\circ} \mathrm{C}$ for $18 \mathrm{~h}$. Then, immobilized streptavidin was added to each sample and incubated at $4{ }^{\circ} \mathrm{C}$ for $2 \mathrm{~h}$, followed by washing 5 times with the actin-binding buffer. The biotin-binding proteins or lysates (30 $\mu \mathrm{g}$ of proteins) were analyzed by immunoblotting. Briefly, the samples were suspended in SDS sample buffer and separated by SDS-polyacrylamide gel electrophoresis. The separated proteins were transferred onto a nitrocellulose membrane and probed with anti-eEF1A, anti- $\beta$ actin, or anti-c-Myc monoclonal antibodies. After being treated with the appropriate secondary antibodies, protein bands were visualized using an enhanced chemiluminescence kit (Amersham Pharmacia), and staining intensities were analyzed using imaging software (Multi Gauge V3.0, Fuji Film, Tokyo, Japan).

\section{Over-Expression and Knockdown of eEF1A1 and eEF1A2}

The full-length and the carboxy-terminal-deleted $(\Delta \mathrm{C})$ pCMV-eEF1A constructs were transiently transfected into HeLa cells in 60-mm dishes using Lipofectamin Plus Reagent (Invitrogen). After 12-h incubation under the standard DMEM culture condition, cells were trypsinized and seeded onto 6- and 12-well plates, and used for immunoblotting and MTT assay, respectively. The siRNAs targeted to eEF1A1 and eEF1A2 were purchased from Dharmacon (Lafayette, CO, USA). siRNA-mediated knockdowns of eEF1A1 and eEF1A2 were carried out according to manufacturer's instructions. Briefly, eEF1A1 and eEF1A2 siRNAs $(25 \mathrm{pmol})$ were transiently transfected into HeLa cells in 6- and 12-well plates using Lipofectamin 2000 (Invitrogen). Samples from the 6-well plates were used for immunoblotting and those from the 12-well plates were used for analyzing cell growth using the MTT viability assay.

\section{Statistical Analysis}

Results are presented as the mean \pm s.e.m. for the indicated number of experiments. The results of multiple experiments were analyzed using non-paired Student's $t$ test or analysis of variance, as appropriate.

\section{RESULTS}

\section{Effects of $\mathrm{pH}_{\mathrm{i}}$ Modulation on Cell Viability}

To evaluate the effects of intracellular $\mathrm{pH}$ on cell viability, HeLa, HEK293, and NIH3T3 cells were incubated in different $\mathrm{CO}_{2}$ concentrations with the standard $44 \mathrm{mM} \mathrm{HCO}_{3}^{-}$containing DMEM for $24 \mathrm{~h}$, and altered viability because of cytoplasmic $\mathrm{pH}$ change was determined by MTT assay. Measurements of $\mathrm{pH}_{\mathrm{i}}$ in HeLa cells showed that incubation in $2 \% \mathrm{CO}_{2}$ increased $\mathrm{pH}_{\mathrm{i}}$ to 7.57 from the control $\mathrm{pH}_{\mathrm{i}}$ value of 7.19 at $10 \% \mathrm{CO}_{2}$. On the other hand, incubation in the $20 \%$ $\mathrm{CO}_{2}$ incubator decreased $\mathrm{pH}_{\mathrm{i}}$ to 6.56 (Table 1). Under the

Table 1 Medium pH $\left(\mathrm{pH}_{\mathrm{M}}\right)$ and intracellular $\mathrm{pH}\left(\mathrm{pH}_{\mathrm{i}}\right)$ in HeLa cells with the absence or presence of cells and cariporide

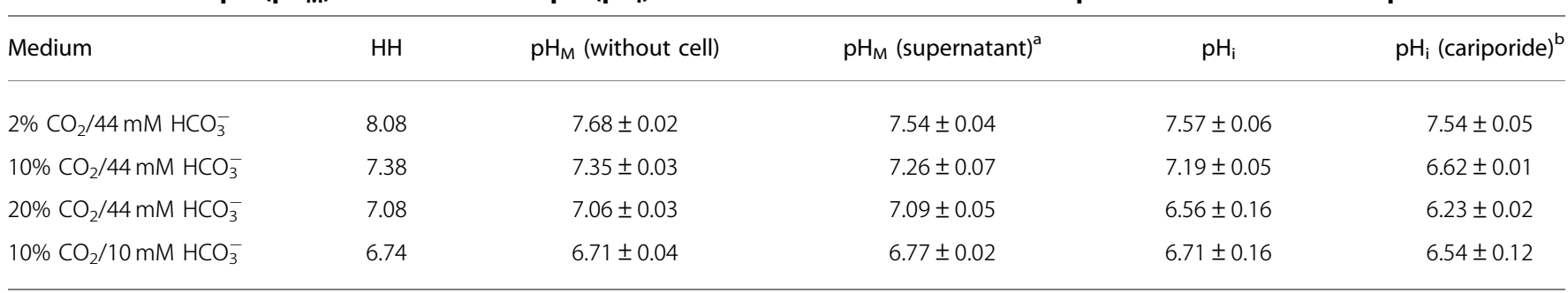

Abbreviation: $\mathrm{HH}$, estimation from the Henderson-Hasselbach equation; $\mathrm{pH}_{\mathrm{i}}$, intracellular $\mathrm{pH}$ and $\mathrm{pH}_{\mathrm{M}}$, medium $\mathrm{pH}$.

Values are expressed as means \pm s.e.m. $(n=3)$.

${ }^{a}$ Cell supernatant was collected after a 12 -h incubation of cells.

${ }^{\mathrm{b}}$ The NHE1 inhibitor, cariporide $(100 \mu \mathrm{M})$, was added during the 12 -h incubation and the $\mathrm{pH}_{\mathrm{i}}$-measuring period. 

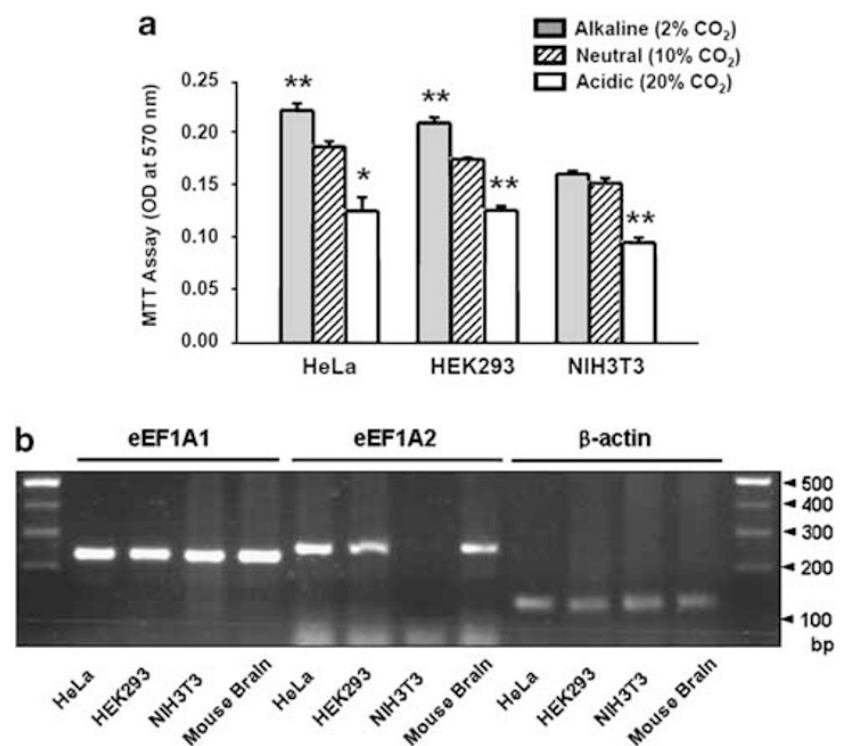

Figure $1 \mathrm{pH}$-dependent cell growth and eukaryotic translation elongation factor $1 \propto$ (eEF1A) expression. (a) Cell viability of NIH3T3, HEK293, and HeLa cells in the $\mathrm{pH}$-modified media was measured using MTT assay. The 12-well plates were loaded with $1.2 \times 10^{5}$ cells $/ \mathrm{mm}^{2}$ and left for $12 \mathrm{~h}$ in Dulbecco's modified Eagle's medium (DMEM) Then, the medium was replaced with DMEM pre-incubated at 2,10 , and $20 \% \mathrm{CO}_{2}$, and cells were incubated in the corresponding $\mathrm{CO}_{2}$ incubation chamber for $24 \mathrm{~h}$. Data shown are mean \pm s.e.m. $(n=9)$. (b) Expression of eEF1A isoforms was examined by reverse transcription (RT)-PCR using human (HeLa and HEK293) and mouse (NIH3T3, mouse brain) eEF1A isoform-specific primers. The primer efficiency of mouse eEF1A2 was verified using RNA samples from mouse brains. RT$\mathrm{PCR}$ on $\beta$-actin was used as control. ${ }^{\star} P<0.05,{ }^{*} P<0.01$ : difference from neutral.

alkaline $2 \% \mathrm{CO}_{2}$ condition, HeLa and HEK293 cells showed significantly higher viability than those under the control $10 \% \mathrm{CO}_{2}$ condition. In contrast, all the three cell types showed low viability under the acidic $20 \% \mathrm{CO}_{2}$ condition (Figure 1a). It is interesting to note that RT-PCR for eEF1A isoforms in these cells showed that HeLa and HEK293 cells express both eEF1A1 and eEF1A2, whereas NIH3T3 cells only had the eEF1A1 isoform (Figure 1b). Considering these results, HeLa cells were chosen to investigate the role of eEF1A in intracellular $\mathrm{pH}_{\mathrm{i}}$-dependent cell viability because $\mathrm{HeLa}$ cells (1) showed robust $\mathrm{pH}_{\mathrm{i}}$-dependent cell viability, (2) had both isoforms of eEF1A, and (3) originated from a human cervical adenocarcinoma.

The $\mathrm{pH}_{\mathrm{i}}$-dependent viability of HeLa cells was further explored over variable time periods and with different intracellular acidifying protocols. As shown in Figure 2a, HeLa cells in the alkaline media showed higher viability than those in the neutral media by an average of $43 \%$ during the 3 -day observation period. Microscopic observations from longer periods showed that this phenomenon lasted until $80 \%$ of cell confluence had been reached. The low viability in acidic media was also reproduced while observing 3-day incubations. It is interesting to note that cells in another acidic
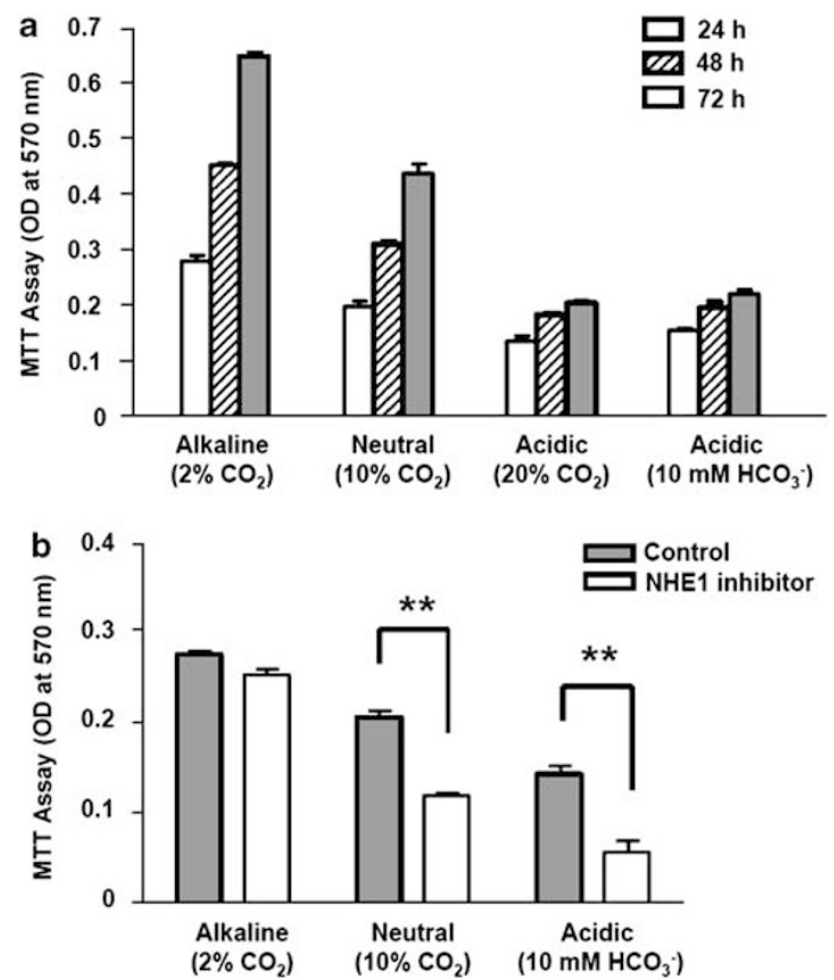

Figure 2 Effects of pH-modification and NHE1 inhibition on HeLa cell viability. (a) HeLa cells were incubated in standard Dulbecco's modified Eagle's medium (DMEM) at 2, 10, and $20 \% \mathrm{CO}_{2}$, and in the $\mathrm{HCO}_{3}^{-}$reducing DMEM at $10 \% \mathrm{CO}_{2}$ for 3 days. DMEM pre-incubated at the appropriate $\mathrm{CO}_{2}$ concentration was changed every $12 \mathrm{~h}$. At 1-day intervals, the viability of the cells was measured by MTT assay. (b) Effects of NHE1 inhibition in various $\mathrm{pH}$-modified media. HeLa cells were incubated in $2 \%$ $\mathrm{CO}_{2}, 10 \% \mathrm{CO}_{2}$, and $\mathrm{HCO}_{3}^{-}$-modified medium in the absence (control, dark histogram) or presence (NHE1 inhibitor, white histogram) of $100 \mu \mathrm{M}$ cariporide. Data shown are means \pm s.e.m. $(n=9)$. ${ }^{* \star P}<0.01$ : difference from control.

medium, with reduced $\mathrm{HCO}_{3}^{-}$rather than increased $\mathrm{CO}_{2}$, also showed low viability (Figure 2a). This result implies that a decrease in $\mathrm{pH}_{\mathrm{i}}$, rather than a high $\mathrm{CO}_{2}$ concentration, is responsible for the low viability.

NHE1 catalyzes the exchange of $\mathrm{Na}^{+}$and $\mathrm{H}^{+}$across the cell and is the predominant $\mathrm{pH}$ regulator in tumor cells. $^{1,4}$ As shown in Table 1, treatment with the NHE1 inhibitor, cariporide, greatly decreases $\mathrm{pH}_{\mathrm{i}}$ under the standard $10 \% \mathrm{CO}_{2}$ DMEM culture condition. Even in the $20 \%$ $\mathrm{CO}_{2}$ acidic media, NHE1 inhibition further decreases $\mathrm{pH}_{\mathrm{i}}$. However, cariporide did not significantly affect the $\mathrm{pH}_{\mathrm{i}}$ in the alkaline medium (Table 1). As the addition of cariporide reduced $\mathrm{pH}_{\mathrm{i}}$, we addressed whether NHE1 inhibition could directly inhibit the proliferation of HeLa tumor cells next. As expected from our $\mathrm{pH}_{\mathrm{i}}$ measurements, cariporide greatly decreased cell viability in neutral or acidic mediums (Figure 2b). These results confirmed that $\mathrm{pH}_{\mathrm{i}}$, which is regulated by NHE1, plays an important role in tumor cell growth. 


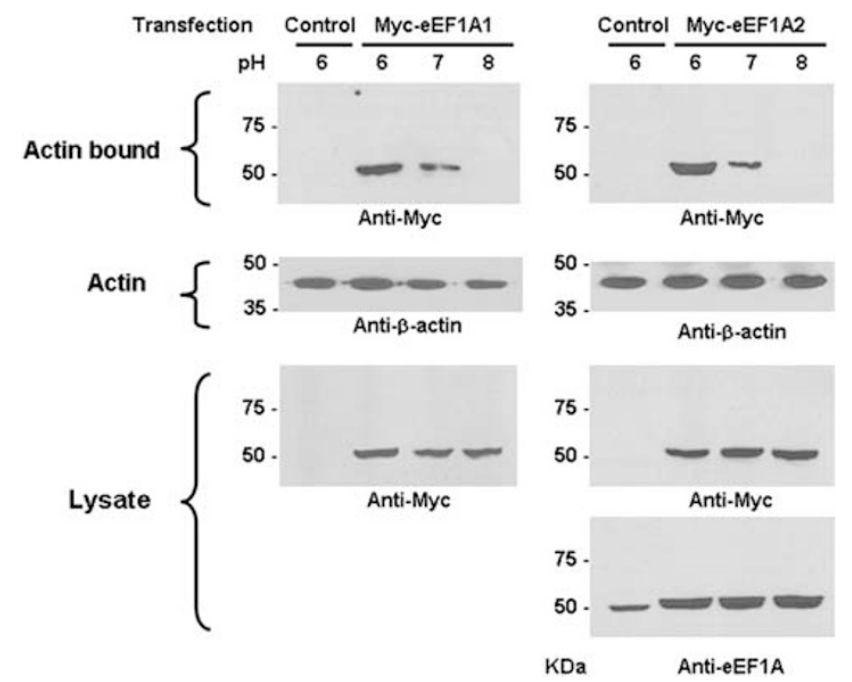

Figure $3 \mathrm{pH}$-dependent actin binding of human eukaryotic translation elongation factor $1 \alpha$ (eEF1As). Constructs expressing Myc-tagged human eEF1As were transiently transfected into HeLa cells. After $48 \mathrm{~h}$, cells were lysed in the actin-binding buffer with $\mathrm{pH}$ values ranging from 6 to 8 , and the lysates were incubated with actin-biotin. After incubation, immobilized streptavidin was added to the sample and biotin-binding proteins or lysates were analyzed by immunoblotting with anti-Myc (Santa Cruz), anti- $\beta$-actin (Santa Cruz), or anti-eEF1A (Upstate) antibodies. The control cells were mock transfected with pcDNA3.1/Zeo(+). Immunoblotting of protein lysates using anti-eEF1A antibody represents the amounts of both endogenous and over-expressed eEF1A proteins.

\section{Effects of $\mathrm{pH}_{\mathrm{i}}$ Modulation on the Actin-Binding Properties of eEF1A and the eEF1A-Dependent Cell Viability}

In Dictyostelium, eEF1A proteins not only shuttle aminoacyltRNAs in protein translation, but also bind to F-actin. This binding is regulated by $\mathrm{pH}_{\mathrm{i}}$ in vitro and in vivo. ${ }^{19}$ When $\mathrm{pH}_{\mathrm{i}}$ increases, the EF1A-mediated cross-links between actin filaments dissociate and EF1A is liberated from actin and binds to aminoacyl-tRNA for protein synthesis. ${ }^{13,15,19}$ Owing to the DNA sequence homology between Dictyostelium EF1A and human eEF1As (Supplementary 2), we sought to determine whether human eEF1A1 and eEF1A2 bind to actin, and whether their association is controlled by $\mathrm{pH}$. HeLa cells were transfected with Myc-tagged eEF1A constructs and the actin binding of eEF1A was measured in the $\mathrm{pH}$-modified buffers. As shown in Figure 3, the majority of eEF1A1 and eEF1A2 proteins were bound to actin in the $\mathrm{pH} 6$ actin-binding buffer. Both eEF1A1 and eEF1A2 protein levels bound to actin at $\mathrm{pH} 7$ were lower than those bound at $\mathrm{pH} 6$, and actin binding was almost non-existent at $\mathrm{pH}$ 8. These results show that human eEF1A1 and eEF1A2 are actin-binding proteins, which have a reduced actin-binding activity in alkaline $\mathrm{pH}$.

Dictyostelium eEF1A has two actin-binding domains, domains I and III; domain III is responsible for the majority of actin-binding activity and the carboxy-terminal 54 residues of domain III (403-456) are the essential actin-binding residues. The Dictyostelium eEF1A $\Delta \mathrm{C}$ protein, which lacks
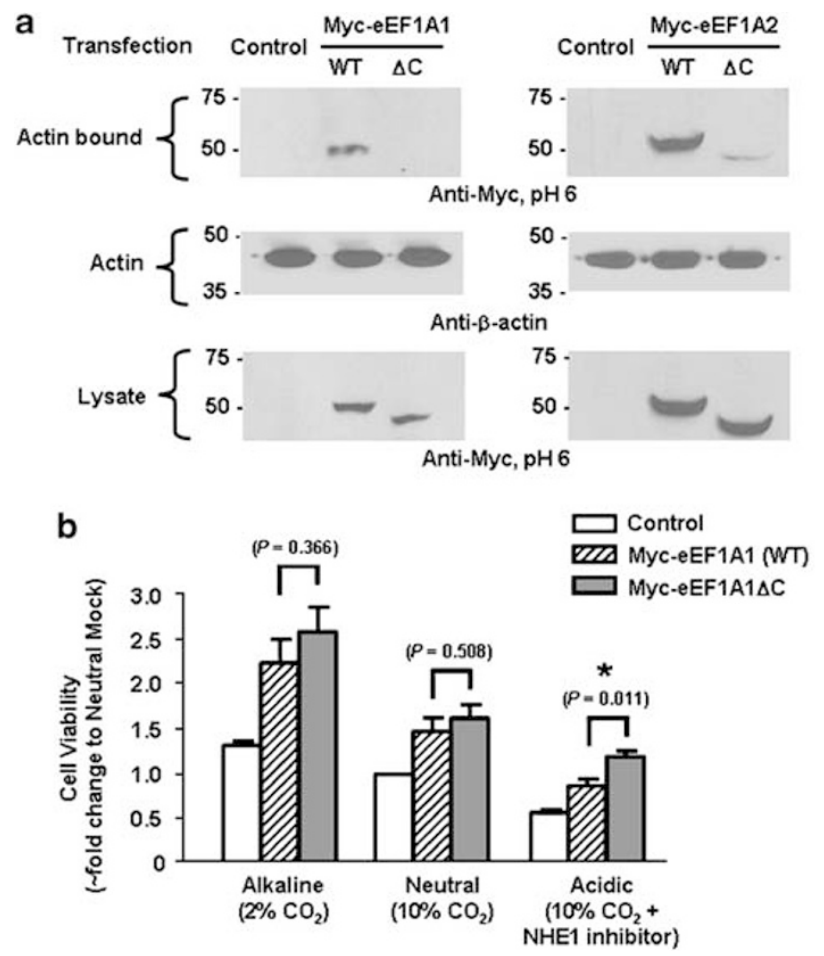

Figure 4 Role of actin binding of eukaryotic translation elongation factor 1 $\alpha($ EFF1A) in $\mathrm{pH}$-dependent cell viability. HeLa cells were seeded onto a 12well plate after the transfection of wild-type (WT) or the carboxy-terminal actin-binding domain-deleted $(\Delta C)$ eEF1A constructs. (a) Actin-binding experiments detailed in Figure 3 were carried out with constructs for WT and $\triangle \mathrm{C}$ eEF1As and in actin-binding buffer at $\mathrm{pH} 6$, in which maximal actin binding is expected. (b) HeLa cells were transfected with constructs for WT and $\triangle \mathrm{C}$ eEF1As and were incubated under each $\mathrm{pH}$-modified condition for $48 \mathrm{~h}$. Cell viability was measured with the MTT assay and the values were normalized to that of the neutral control for each set of experiments. Data shown are means \pm s.e.m. $(n=9)$. ${ }^{\star} P<0.05$ : difference from WT-Myc-eEF1A.

the C-terminal 54 amino acids, lost more than $90 \%$ of the actin-binding activity. ${ }^{23}$ Based on the sequence alignment, residues 408-462 of human eEF1A1 and 408-463 of human eEF1A2 make up the corresponding carboxy-terminal 54 residues of Dictyostelium eEF1A (Supplementary 2). Therefore, we constructed human Myc-eEF1A1 $\Delta \mathrm{C}(\Delta 408-462)$ and Myc-eEF1A2 $\Delta \mathrm{C}(\Delta 408-463)$ clones and measured their actin-binding activity. As shown in Figure 4a, both eEF1A1 $\Delta \mathrm{C}$ and eEF1A2 $\Delta \mathrm{C}$ almost completely lost actinbinding activity, even at a $\mathrm{pH}$ of 6 . Next, we measured the effects of the carboxy-terminus deletion on eEF1A-dependent cell viability. It has been shown that over-expression of eEF1A is associated with increased cell viability. ${ }^{14}$ As shown in Figure $4 \mathrm{~b}$, transfection of the full-length wild-type eEF1A1 construct induced an increase in cell viability at every $\mathrm{pH}_{\mathrm{i}}$. It is interesting to note that transfection of the carboxy-terminal deleted $(\Delta \mathrm{C})$ eEF1A1 construct further increased cell viability only at acidic $\mathrm{pH}_{\mathrm{i}}$. These results indicate that dissociation from actin is important for eEF1A-dependent cell viability. At acidic $\mathrm{pH}_{\mathrm{i}}$, where most of the eEF1A is bound to 


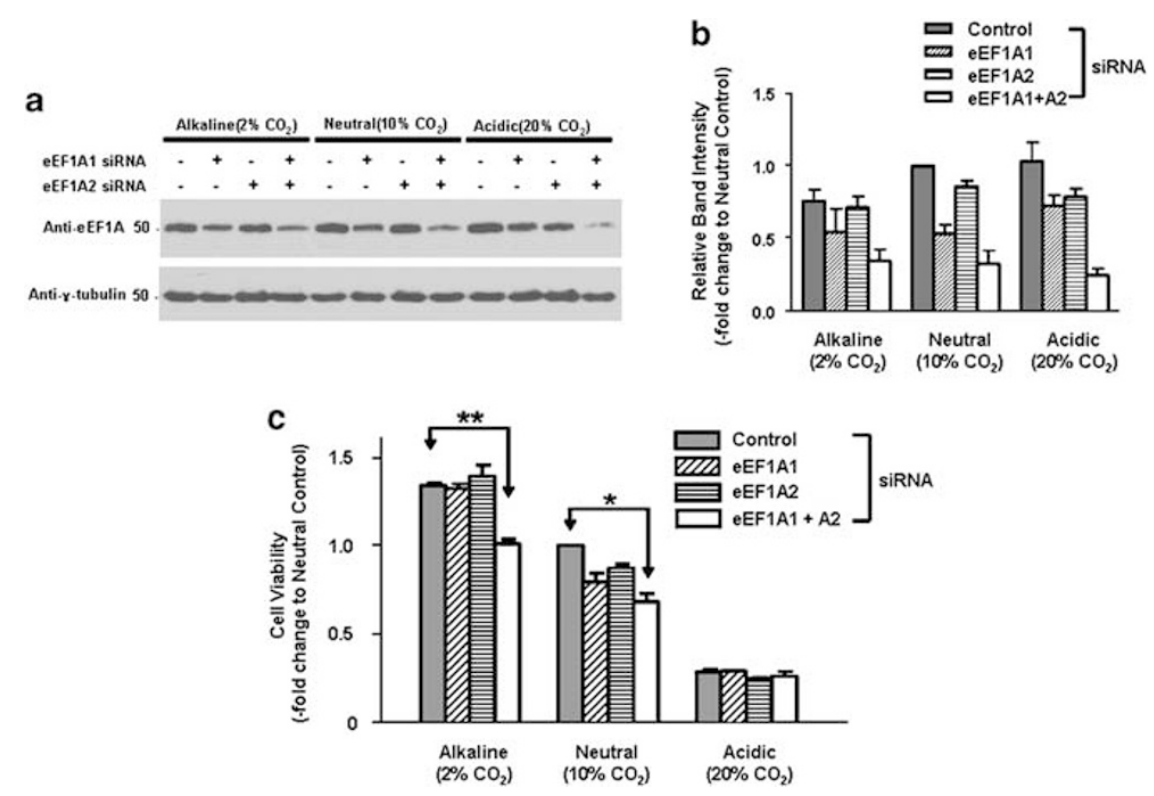

Figure 5 Effects of eukaryotic translation elongation factor $1 \alpha$ (eEF1A) knockdowns on pH-dependent cell viability. HeLa cells were transfected with eEF1A1 and eEF1A2 siRNAs and incubated according to each pH-modified condition for $48 \mathrm{~h}$. Control cells were transfected with the scrambled siRNA. (a, b) Effects of the siRNA-mediated knockdown of endogenous eEF1As were examined using immunoblotting with anti-eEF1A antibody (Upstate). Control immunoblot was blotted with anti- $\gamma$-tubulin antibody from Sigma (St Louis, MO, USA). Results of multiple $(n=3)$ experiments are summarized in panel B. (c) Cell viability was measured with the MTT assay. Data shown are means \pm s.e.m. $(n=4)$. ${ }^{*} P<0.05,{ }^{*} P<0.01$ : difference from control.

actin, the deletion of the actin-binding domain significantly increases cell viability, whereas at alkaline $\mathrm{pH}_{\mathrm{i}}$, deletion of the actin-binding domain does not affect cell viability because most of eEF1A is already dissociated from actin.

\section{eEF1A is Necessary for $\mathbf{p H}_{\mathbf{i}}$-Dependent Cell Viability}

To investigate the function of endogenous eEF1A in human cancer cells, we used RNA interference to specifically deplete eEF1A protein in HeLa cells. To confirm the siRNA-mediated eEF1A knockdown, cells were harvested 2 days after transfection with the control scrambled siRNA and eEF1A isoform-specific siRNAs in each condition, and the protein samples were blotted with the anti-eEF1A antibody that detects both eEF1A1 and eEF1A2. As shown in Figure 5a, treatment with eEF1A1 siRNA alone or eEF1A2 siRNA alone induced only a small change in the total eEF1A protein level. However, co-transfection with both eEF1A1 and eEF1A2 siRNAs decreased the amount of total eEF1A proteins by $54 \%$ (alkaline condition)-76\% (acidic condition) (Figure $5 \mathrm{~b}$ ). The eEF1A1 and eEF1A2 siRNA-transfected cells were incubated in 2,10 , and $20 \% \mathrm{CO}_{2}$ incubation chambers for $48 \mathrm{~h}$, and the respective cell viability was measured. It is interesting to note that knockdowns of eEF1A greatly decreased cell viability in alkaline and neutral media, but not in acidic media (Figure $5 c$ ). These results suggest that endogenous eEF1A has a key role in cell viability under alkaline or neutral conditions, where a considerable amount of eEF1A is in the unbound free form, but not in the acidic condition where most of eEF1A is in the actin-bound state.

\section{DISCUSSION}

Abnormally high intracellular alkalinization is a well-documented phenotype in tumor cells, and is thought to play a pivotal role in neoplastic transformation and maintenance of neoplastic progression. ${ }^{1,10,24}$ For example, increased $\mathrm{pH}_{\mathrm{i}}$ of tumor cells is associated with increased in vivo tumor growth, DNA synthesis, and cell-cycle progression. ${ }^{1}$ In addition, cytoplasmic alkalinization is an important signal in controlling the rate of cell division and activation of DNA and protein synthesis in fibroblast and Dictyostelium. ${ }^{15,25}$ In this study, we provide several lines of evidence that eEF1A plays a direct and pivotal role in intracellular alkalinization-induced tumor cell growth.

The primary function of eEF1A is to shuttle aminoacyl t-RNA during protein translation. The two eEF1A isoforms, eEF1A1 and eEF1A2, appears to have similar activities in protein elongation. In addition to its major role as a protein translation factor, eEF1A stimulates a filopodia formation through cooperation with PI4KIII $\beta$ and also regulates re-cycling of M4 muscarinic acetylcholine receptors. These non-canonical roles of eEF1A based on the strong relation of eEF1A with actin, and furthermore, eEF1A actually binds to actin. ${ }^{26-28}$ It is interesting to note that the binding of eEF1A to F-actin has pH-dependent kinetics. For example, Dictyostelium eEF1A showed a $K_{d}$ value of $0.2 \mu \mathrm{M}$ at $\mathrm{pH} 6.5$, and this value increases greatly to a $K_{\mathrm{d}}$ of $>2.2 \mu \mathrm{M}$ at $\mathrm{pH}$ 7.8. ${ }^{19}$ As shown in Figure 3, we also confirmed the pH-dependent actin-binding for human eEF1A1 and eEF1A2. It has been proposed that a weakened association of eEF1A with actin may be related to cancer cell growth and metastasis via an altered organization of the actin cytoskeleton and the 
differential translation of mRNAs. ${ }^{14}$ In fact, it has been shown that the binding affinity of eEF1A to F-actin in tumor cells is lower than that for eEF1A in normal cells. ${ }^{14}$ The results in this study indicate that increased $\mathrm{pH}_{\mathrm{i}}$ of tumor cells is an important factor for the dissociation of eEF1A from the actin cytoskeleton. In immunofluoroscence experiments, we found that eEF1A was highly co-localized with F-actin in HeLa cells (data not shown), as previously reported. ${ }^{14}$ Treatment with alkaline conditions seemed to evoke a global increase of eEF1A fraction in cytosol, which partially increased cytosolic haziness in the immunofluoroscence images. However, significant fractions of eEF1A were still bound to F-actin. It seems that a large pool of eEF1A is intercalated with and not dissociable from F-actin. For this reason, we could not observe dramatic changes in the immunofluoroscence experiments, such as complete dissociation of eEF1A from $\mathrm{F}$-actin in alkaline conditions. However, this does not weaken the findings of this study. As shown in Figure 3, a significant fraction of eEF1A exists in the dissociable pool of F-actin (soluble form in cytosol), and its binding to actin is under dynamic control of intracellular $\mathrm{pH}$.

Recently, several studies have shown that the two isoforms of eEF1A serve as growth-enhancing genes, where an increase in the copy number of eEF1A1 and eEF1A2 can play a critical role in malignant tumor progression. ${ }^{18} e E F 1 A 1$, which maps to $6 \mathrm{q} 14$, is amplified in some childhood brain tumors, and eEF1A1 is over-expressed in pancreas, breast, lung, and colon tumors. ${ }^{29-31}$ In prostate carcinoma, the dominant prostate tumor-inducing gene 1 (PTI-1), with a 97.7\% DNA sequence homology to eEF1A1, was identified by PCR. ${ }^{30}$ Its expression occurs in breast, colon, and lung cancer cells, but not in normal cells, and it can transform rodent fibroblasts. Antisense-mediated blocking of PTI-1 inhibits tumorigenesis and results in the reversion of tumor cells to a normal cellular phenotype. ${ }^{32}$ As it bears a strong sequence similarity to eEF1A1, eEF1A2 is also involved in cancer. The amplification of the eEF1A2 gene, which maps to $20 \mathrm{q} 13$, occurs in $20-30 \%$ of ovarian cancer cases ${ }^{18}$ and two-thirds of breast tumors. ${ }^{33}$ In addition to eEF1As, the increased expression of another elongation factor, EIF4E, an mRNA cap-binding factor, is also associated with tumors in the breast, colon, larynx, and lungs. ${ }^{3-36}$ In general, increased expression of the elongation factor is thought to be associated with tumorigenesis by enhancing the translation of genes promoting cellular growth. $^{18,37}$

Low $\mathrm{CO}_{2}$ incubations alkalinized the $\mathrm{HeLa}$ human cervical adenocarcinoma cells and increased cell viability (Figures 1 and 2). Incubations at $2 \% \mathrm{CO}_{2}$ in the standard $44 \mathrm{mM} \mathrm{HCO}_{3}^{-}$containing DMEM increased the $\mathrm{pH}_{\mathrm{i}}$ of HeLa cells from 7.19 to 7.57 (Table 1), which is close to the physiological upper limit value of 7.65 observed in tumor cells, ${ }^{1}$ indicating that the $\mathrm{CO}_{2}$ modification is a suitable system for this study. Moreover, the viable patterns of cells under the following three different acidic conditions are: (1) $\mathrm{HCO}_{3}^{-}$reduction in DMEM with the standard $10 \% \mathrm{CO}_{2}$ incubation, (2) standard $\mathrm{HCO}_{3}^{-} / \mathrm{CO}_{2}$ DMEM treated with the NHE1 inhibitor, and (3) high $\mathrm{CO}_{2}$ incubation (20\%) with the standard $44 \mathrm{mM} \mathrm{HCO}_{3}^{-}$containing DMEM, were very similar (Figures 1 and 2). Accordingly, changes in cell viability cannot be attributed to $\mathrm{CO}_{2}$ toxicity, $\mathrm{O}_{2}$ deficiency, or bicarbonate ion concentration, but are due to cytoplasmic alkalinization or acidosis.

Inhibition of NHE1 by cariporide affected both the cell growth rate and the intracellular $\mathrm{pH}$ of tumor cells (Figures 2 and 4). NHE1 is quiescent at resting $\mathrm{pH}_{\mathrm{i}}$ and is activated only upon cytosolic acidification in normal cells, whereas NHE1 is hyperactivated, even at resting $\mathrm{pH}_{\mathrm{i}}$, in transformed and tumor cells, which results in an alkalinization of $\mathrm{pH}_{\mathrm{i}}$ and acidification of $\mathrm{pH}_{\mathrm{e}}{ }^{1,24}$ Owing to the insufficient and disorganized vascularization of tumor vessels and the increased metabolism of tumor cells, increased NHE1 activity further acidifies the microenvironment of tumor cells. This has been shown to increase the metastatic potential of tumor cells by promoting neoangiogenesis, anchorage-independent growth, genetic instability, and invasion. ${ }^{1}$ Moreover, the cellular alkalinization of tumor cells induced by hyperactivation of NHE1 has been shown to be directly related to increased protein synthesis and tumor cell growth. ${ }^{1,24,38}$ The direct regulation of cytoskeletal dynamics and signal activation by NHE1 as a scaffolding protein, independent of its ion-transporting activities, has been suggested to be involved in NHE1-mediated tumor cell growth and metastasis. ${ }^{1}$ The results in this study suggest that $\mathrm{pH}$-dependent eEF1A redistribution may play a role in NHE1-mediated tumor cell growth.

In conclusion, our study provides sufficient evidence that human eEF1A plays a role in the intracellular alkalinizationinduced tumor cell growth. We showed that eEF1A is dissociated from actin under alkaline conditions and that eEF1A-mediated cell growth is augmented with an increase in levels of unbound free-form eEF1A in HeLa cells. Moreover, results of the eEF1A knockdown experiments revealed that eEF1A is necessary for alkalinization-induced cell growth. These results provide new insight into our understanding of intracellular alkalinization-induced tumor cell growth. A detailed understanding of the role of eEF1A in tumorigenesis will facilitate the development of specific modalities to inhibit tumor growth.

Supplementary Information accompanies the paper on the Laboratory Investigation website (http://www.laboratoryinvestigation.org)

\section{ACKNOWLEDGEMENT}

This work was supported by grants A030001 from the Korea Health 21 R\&D Project, Ministry for Health, Welfare and Family Affairs, Korea, and KRF-2008314-C00284 from the Korea Research Foundation Grant funded by the Korean Government, Korea.

1. Cardone RA, Casavola V, Reshkin SJ. The role of disturbed $\mathrm{pH}$ dynamics and the $\mathrm{Na}^{+} / \mathrm{H}^{+}$exchanger in metastasis. Nat Rev Cancer 2005;5: 786-795. 
2. Webb SD, Sherratt JA, Fish RG. Modelling tumour acidity and invasion Novartis Found Symp 2001;240:169-181; discussion 181-165.

3. Madshus IH. Regulation of intracellular $\mathrm{pH}$ in eukaryotic cells. Biochem J 1988;250:1-8.

4. Pouyssegur J, Dayan F, Mazure NM. Hypoxia signalling in cancer and approaches to enforce tumour regression. Nature 2006;441:437-443.

5. Torigoe $\mathrm{T}$, Izumi $\mathrm{H}$, Ise $\mathrm{T}$, et al. Vacuolar $\mathrm{H}^{+}$-ATPase: functional mechanisms and potential as a target for cancer chemotherapy. Anticancer Drugs 2002;13:237-243.

6. Orlowski J, Grinstein S. $\mathrm{Na}^{+} / \mathrm{H}^{+}$exchangers of mammalian cells. J Biol Chem 1997;272:22373-22376.

7. Slepkov ER, Rainey JK, Sykes BD, et al. Structural and functional analysis of the $\mathrm{Na}^{+} / \mathrm{H}^{+}$exchanger. Biochem J 2007;401:623-633.

8. Wakabayashi S, Shigekawa M, Pouyssegur J. Molecular physiology of vertebrate $\mathrm{Na}^{+} / \mathrm{H}^{+}$exchangers. Physiol Rev 1997;77:51-74.

9. Ammar YB, Takeda S, Hisamitsu T, et al. Crystal structure of CHP2 complexed with $\mathrm{NHE1-cytosolic} \mathrm{region} \mathrm{and} \mathrm{an} \mathrm{implication} \mathrm{for} \mathrm{pH}$ regulation. EMBO J 2006;25:2315-2325.

10. Reshkin SJ, Bellizzi A, Caldeira $\mathrm{S}$, et al. $\mathrm{Na}^{+} / \mathrm{H}^{+}$exchanger-dependent intracellular alkalinization is an early event in malignant transformation and plays an essential role in the development of subsequent transformation-associated phenotypes. FASEB J 2000;14:2185-2197.

11. Moolenaar WH, Tsien RY, van der Saag PT, et al. $\mathrm{Na}^{+} / \mathrm{H}^{+}$exchange and cytoplasmic $\mathrm{pH}$ in the action of growth factors in human fibroblasts. Nature 1983;304:645-648.

12. Hershey JW. Translational control in mammalian cells. Annu Rev Biochem 1991;60:717-755.

13. Edmonds BT, Bell A, Wyckoff J, et al. The effect of F-actin on the binding and hydrolysis of guanine nucleotide by Dictyostelium elongation factor 1A. J Biol Chem 1998;273:10288-10295.

14. Edmonds BT, Wyckoff J, Yeung YG, et al. Elongation factor-1 alpha is an overexpressed actin binding protein in metastatic rat mammary adenocarcinoma. J Cell Sci 1996;109:2705-2714.

15. Liu G, Tang J, Edmonds BT, et al. F-actin sequesters elongation factor 1alpha from interaction with aminoacyl-tRNA in a pH-dependent reaction. J Cell Biol 1996;135:953-963.

16. Lee $\mathrm{S}$, Francoeur AM, Liu S, et al. Tissue-specific expression in mammalian brain, heart, and muscle of S1, a member of the elongation factor-1 alpha gene family. J Biol Chem 1992;267:24064-24068.

17. Knudsen SM, Frydenberg J, Clark BF, et al. Tissue-dependent variation in the expression of elongation factor-1 alpha isoforms: isolation and characterisation of a cDNA encoding a novel variant of human elongation-factor 1 alpha. Eur J Biochem 1993;215:549-554.

18. Anand N, Murthy S, Amann G, et al. Protein elongation factor EEF1A2 is a putative oncogene in ovarian cancer. Nat Genet 2002;31:301-305.

19. Edmonds BT, Murray J, Condeelis J. pH regulation of the F-actin binding properties of Dictyostelium elongation factor 1 alpha. J Biol Chem 1995;270:15222-15230.

20. Demma M, Warren V, Hock R, et al. Isolation of an abundant 50,000dalton actin filament bundling protein from Dictyostelium amoebae. J Biol Chem 1990;265:2286-2291.

21. Kim J, Jung YS, Han W, et al. Pharmacodynamic characteristics and cardioprotective effects of new NHE1 inhibitors. Eur J Pharmacol 2007;567:131-138.
22. Han W, Kim KH, Jo MJ, et al. Shank2 associates with and regulates $\mathrm{Na}^{+} / \mathrm{H}^{+}$exchanger 3. J Biol Chem 2006;281:1461-1469.

23. Liu G, Grant WM, Persky D, et al. Interactions of elongation factor 1alpha with F-actin and beta-actin mRNA: implications for anchoring mRNA in cell protrusions. Mol Biol Cell 2002;13: 579-592.

24. Harguindey $\mathrm{S}$, Orive $\mathrm{G}$, Luis Pedraz J, et al. The role of $\mathrm{pH}$ dynamics and the $\mathrm{Na}^{+} / \mathrm{H}^{+}$antiporter in the etiopathogenesis and treatment of cancer. Two faces of the same coin-one single nature. Biochim Biophys Acta 2005;1756:1-24.

25. Aerts RJ, Durston AJ, Moolenaar WH. Cytoplasmic $\mathrm{pH}$ and the regulation of the Dictyostelium cell cycle. Cell 1985;43(3 Pt 2):653-657.

26. Jeganathan S, Lee JM. Binding of elongation factor eEF1A2 to phosphatidylinositol 4-kinase beta stimulates lipid kinase activity and phosphatidylinositol 4-phosphate generation. J Biol Chem 2007;282:372-380.

27. Jeganathan S, Morrow A, Amiri A, et al. Eukaryotic elongation factor $1 \mathrm{~A} 2$ cooperates with phosphatidylinositol-4 kinase III beta to stimulate production of filopodia through increased phosphatidylinositol-4,5 bisphosphate generation. Mol Cell Biol 2008;28:4549-4561.

28. McClatchy DB, Fang G, Levey Al. Elongation factor $1 \mathrm{~A}$ family regulates the recycling of the M4 muscarinic acetylcholine receptor. Neurochem Res 2006;31:975-988.

29. Mohler JL, Morris TL, Ford III OH, et al. Identification of differentially expressed genes associated with androgen-independent growth of prostate cancer. Prostate 2002;51:247-255

30. Thornton S, Anand N, Purcell D, et al. Not just for housekeeping: protein initiation and elongation factors in cell growth and tumorigenesis. J Mol Med 2003;81:536-548.

31. Xie D, Jauch A, Miller CW, et al. Discovery of over-expressed genes and genetic alterations in breast cancer cells using a combination of suppression subtractive hybridization, multiplex FISH and comparative genomic hybridization. Int J Oncol 2002;21:499-507.

32. Su Z, Goldstein NI, Fisher PB. Antisense inhibition of the PTI-1 oncogene reverses cancer phenotypes. Proc Natl Acad Sci USA 1998;95:1764-1769.

33. Tomlinson VA, Newbery HJ, Wray NR, et al. Translation elongation factor eEF1A2 is a potential oncoprotein that is overexpressed in twothirds of breast tumours. BMC Cancer 2005:5:113.

34. Li BD, Liu L, Dawson M, et al. Overexpression of eukaryotic initiation factor 4E (elF4E) in breast carcinoma. Cancer 1997;79: 2385-2390.

35. Nathan CO, Sanders K, Abreo FW, et al. Correlation of p53 and the proto-oncogene elF4E in larynx cancers: prognostic implications. Cancer Res 2000:60:3599-3604.

36. Rosenwald IB, Hutzler MJ, Wang S, et al. Expression of eukaryotic translation initiation factors $4 \mathrm{E}$ and 2alpha is increased frequently in bronchioloalveolar but not in squamous cell carcinomas of the lung. Cancer 2001;92:2164-2171.

37. Sonenberg N. Translation factors as effectors of cell growth and tumorigenesis. Curr Opin Cell Biol 1993;5:955-960.

38. Gatenby RA, Gillies RJ. Why do cancers have high aerobic glycolysis? Nat Rev Cancer 2004;4:891-899. 